\title{
APPLICATION OF THE INTERNET OF THINGS CONCEPT IN CARSHARING SYSTEM
}

\author{
GrGUREVIC, I.; PERAKOVIC, D.; \\ FORENBACHER, I. \& MILINOVIC, T.
}

Abstract: This paper analyzes the possible application of the concept of Internet of Things (IoT) in the traffic environment based on the example of the carpooling/ridesharing system with the use of a private vehicle - the carsharing model. The research has been conducted by surveying and interviewing traffic system participants (i.e. users) who frequently use modern communication devices, technologies, and services. Targeted users are familiar with the issues of the carpooling/ridesharing system. Based on the research analysis results, it is possible to identify the factors of the potential application of the IoT solutions in the development of carsharing model.

Key words: Internet of Things (IoT), Information and Communication Technologies; Traffic Environment; Carsharing System
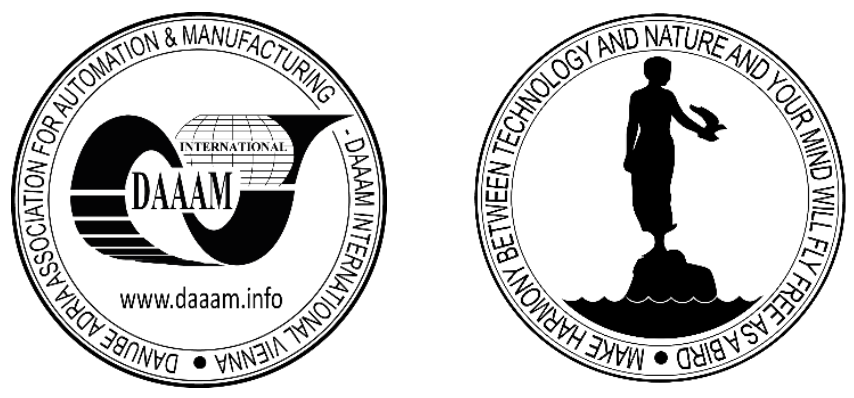

Authors' data: Dr. Sc. Grgurevic, I[van]; Assoc. Prof. Dr. Sc. Perakovic, D[ragan]; Dipl.-Ing. Forenbacher, I[van]; Dipl.-Ing. Milinovic, T[omislav], University of Zagreb, Faculty of Transport and Traffic Sciences, Vukeliceva 4, 10000, Zagreb, Republic of Croatia, ivan.grgurevic@fpz.hr; dragan.perakovic@fpz.hr; ivan.forenbacher@fpz.hr

This Publication has to be referred as: Grgurevic, I[van]; Perakovic, D[ragan]; Forenbacher, I[van] \& Milinovic, T[omislav] (2015). Application of the Internet of Things Concept in Carsharing System, Chapter 34 in DAAAM International Scientific Book 2015, pp.401-414, B. Katalinic (Ed.), Published by DAAAM International, ISBN 978-3-902734-05-1, ISSN 1726-9687, Vienna, Austria

DOI: $10.2507 /$ daaam.scibook.2015.34 
Grgurevic, I.; Perakovic, D.; Forenbacher, I. \& Milinovic, T.: Application of the Int...

\section{Introduction}

Internet of Things (also known by abbreviation IoT) represents various devices which can communicate and share data among themselves, and this concept enables many dynamic and applicable configuration possibilities. The major objectives for the IoT are the creation of smart environments/spaces based on self-aware things (for example, smart transport, smart city, etc.) for new and innovative applications. The IoT involves the increasing prevalence of objects and entities (things) provided with unique identifiers and the ability to automatically transfer data over a network. The objects used in the IoT concept are, for example, Radio-frequency identification (RFID) sensors, detectors, etc. Much of the increase in IoT communication comes from computing devices and embedded sensor systems used in vehicle to vehicle (V2V) communication, machine-to-machine (M2M) communication and wearable computing devices.

Concept IoT finds its place in a growing number of different fields of technology, so its place is assured in the field of transport and traffic as well. One of the biggest problems today is the growing number of passenger vehicles/cars which is proportional with the growth of the population and which causes major traffic congestions, noise and increase the travelling time. Carsharing is the transport model which enables rideshare of a single vehicle for multiple passengers. All passengers share the same or similar starting point and they share the ride in order to reduce the number of vehicles on the road and to reduce their travelling expenses. In fact, carsharing is the most ordinary paratransit mode in which passengers form different user groups, so that they can share a vehicle which operates on their designated routes. Carsharing represents one of the system options of ride sharing with passenger vehicles and it is based on the sharing of one passenger vehicle or car which is owned by the third party (business subject). This allows users (mostly in urban areas) to ride by a shared vehicle instead of their own vehicle, and the vehicle can be obtained through standardized key card on the specially designated stations with defined wage or reimbursement. IoT concept includes a range of new possibilities for carsharing in relation to the current situation. The main purpose of the IoT is to provide connectivity for everyone to everything at any time and any place, what is particularly important in the carsharing system (what has not been the case).

The City of Zagreb, being the capital with 790,017 inhabitants (in 2011) and with 337,591 registered vehicles (in 2013), has recorded a significant number of motorization in the past ten years. High motorization levels and increase in the living standard of the citizens have significantly affected the modal split in the City of Zagreb. This paper is motivated by the statistics associated with the occupation of the passenger vehicles in the City of Zagreb and with the possible application of the sharing rides of the passenger vehicles - carsharing. The amount of occupied vehicles in the City of Zagreb is rather low, in 1999 it was 1.44 , and this number has been slightly decreasing over the years. In 2009 it was 1.37, in 2010 it was 1.40 and finally in 2013 it was 1.42. (Slavulj et al., 2000; Grgurevic, 2013). In the City of Zagreb does not exist carsharing/carpooling system. There are many initiatives which promote options of ridesharing and especially carpooling model (casual, informal, real-time and flexible carpooling). Carpooling, known also as ridesharing, can be defined in case when two or more people travel together in a passenger vehicle/car. The initiatives and demand 
for carpooling/ridesharing services whose aim is to gather passengers with similar commuting routines and time schedules has suddenly increased in the recent years.

As a strategy in the management of transport demand carsharing represents a sustainable and alternative transport mode and a measure that can lead to savings in more different segments (economical, ecological, spatial and traffic) and holders (for individuals, companies, towns, etc.) (Grgurevic, 2013).

Because we are researching possibilities of some relatively new technologies and technological solutions that need adequate infrastructure, in this paper we will conduct analysis of the application of the IoT solutions for the purpose of improving the carsharing system. Modern technologies that are needed for the purpose of the carsharing system include services that are based on information, communication and location-navigational services. The purpose of the research includes overview of the development and possible application of the IoT concept in the traffic environment with reference to carsharing system as one of the models in ridesharing with passenger vehicles. The aim of the research is to explore the application of the IoT solutions for the purpose of carsharing system development. The research has been conducted by surveying and interviewing formal carpooling users who use of modern communication devices, technologies, and services.

\section{Background and related work}

Previous studies and available analytics observe IoT concept according to different segments which can be divided into technology (Tan \& Koo, 2014; Yang et al., 2011; KuBo, 2014), network (Nam et al., 2014; Kim \& Lee, 2012), architecture (Xua et al., 2014) and application (Chen et al., 2013; McEwen \& Cassimally, 2013; Kos et al., 2013). The IoT concept finds substantial application in the fields of transport and logistics (Atzoria et al., 2010). The intensity of the development of the transport system bodily and the intensity of carsharing model development requires increased application of the information and communication technology and services. In order to achieve efficiency in carsharing with passenger vehicles it is important to transfer relevant and vital information in real-time. Statistical data from 2010 show that the number of daily physical objects and devices that are connected to Internet amounts to about 12.5 billion and the data from 2014 amount to about 25 billion (Atzoria et al., 2010; Cisco, 2011). Future predictions say that this number will be doubled by 2020 by 50 billion of connected objects, devices, or entities (Cisco, 2011). By using IoT concept, i.e. Internet and various applications, it is possible to establish connection between different transport entities or vehicles. Various mobile applications (for example: Avego, Zimride, Sidecar, Flinc, etc.) can be used for realizing functionality browser based on the location of the users, thus making it possible to determine the current starting location of the user, their itinerary and destination. Mobile applications can show direction and the current location of other carsharing users in real-time. In case of emergency, such as traffic accident or traffic congestion, the user can adapt to the new situation and alter the route, delay the journey or even cancel the journey or ride. By using mobile applications it is possible to increase the transparency of the contents and the possibility to localize the users. Then it is possible to search the journeys and group the users by using various characteristics. The IoT concept 
Grgurevic, I.; Perakovic, D.; Forenbacher, I. \& Milinovic, T.: Application of the Int...

represents new development possibilities of the carsharing system based on the information and communication technologies.

Table 1 shows more significant studies that are associated with the application of the IoT concept in different branches of transport. Transport branches included in the analysis of the existing studies are: Information and Communications Traffic, Intelligent Transport Systems, Road Transport, Urban Transport and Transport Logistics.

\begin{tabular}{|c|c|c|c|}
\hline $\begin{array}{l}\text { Traffic } \\
\text { branches }\end{array}$ & Studies & Year & Narrow field of research \\
\hline \multirow{4}{*}{$\begin{array}{l}\text { Information and } \\
\text { Communications } \\
\text { Traffic }\end{array}$} & Gao et al. & 2012 & $\begin{array}{l}\text { Electric Vehicles: Wide Area Charging-Swap } \\
\text { Information Perception, Transmission and } \\
\text { Application }\end{array}$ \\
\hline & Shi-ling & 2012 & Smart City \\
\hline & Ming \& Xu & 2012 & Technology in Transportation Industry \\
\hline & $\begin{array}{l}\text { Ping \& Xiao- } \\
\text { dong }\end{array}$ & 2012 & IoT Security \\
\hline \multirow{3}{*}{$\begin{array}{l}\text { Intelligent } \\
\text { Transport } \\
\text { Systems }\end{array}$} & Huang & 2013 & $\begin{array}{l}\text { Application in Intelligent Transportation, } \\
\text { Internet of Vehicle }\end{array}$ \\
\hline & Lian-Zhou & 2013 & Intelligent Monitoring System \\
\hline & Zhang et al. & 2011 & $\begin{array}{l}\text { Intelligent Transport System (ITS), Internet of } \\
\text { Things (IoT), Smart Transport System }\end{array}$ \\
\hline \multirow{3}{*}{ Road Transport } & Sukode \& Gite & 2015 & Traffic Monitoring System, Congestion Control \\
\hline & $\begin{array}{l}\text { Geng-yong \& } \\
\text { Yu-ma }\end{array}$ & 2013 & $\begin{array}{l}\text { Safety Emergency Management System, } \\
\text { Road Dangerous Goods Transport }\end{array}$ \\
\hline & Sun et al. & 2012 & $\begin{array}{l}\text { Parking Guidance Control System, } \\
\text { Parking Space Detection }\end{array}$ \\
\hline \multirow{4}{*}{ Urban Transport } & $\begin{array}{l}\text { Selvapriya \& } \\
\text { Mundada }\end{array}$ & 2015 & Bus Transport System \\
\hline & Zhang \& Chen & 2014 & $\begin{array}{l}\text { Modern Traffic Technology, Urban Public } \\
\text { Transport, }\end{array}$ \\
\hline & Wang \& $\mathrm{Hu}$ & 2014 & Path Optimization, Traffic Guidance \\
\hline & Li et al. & 2010 & Public Transportation \\
\hline \multirow{3}{*}{$\begin{array}{l}\text { Transport } \\
\text { Logistics }\end{array}$} & Yu \& Bai & 2012 & $\begin{array}{l}\text { Intelligent Logistics, Radio Frequency } \\
\text { Identification (RFID) }\end{array}$ \\
\hline & $\mathrm{Yu}$ & 2011 & $\begin{array}{l}\text { Logistics Management System, } \\
\text { Radio Frequency Identification (RFID) }\end{array}$ \\
\hline & Xie & 2011 & Modern logistics \\
\hline
\end{tabular}

Tab. 1. Studies associated with the application of the IoT concept in different branches of transport

By analysing the available relevant studies a lack of research on the subject of IoT concept application for the purpose of carsharing system has been established. This represents a motive and a reason for the authors to research the issue of applying the IoT concept for the purposes of the carsharing system. 


\section{Survey description}

Until recently, carsharing systems had limited usage because of the lack of efficient data processing and information-communication support. However, recent development of information, communication and location-navigation services have contributed towards upgrade and acceptance of the carsharing system. In the last 10 years a substantial number of various types and categories of papers have been analyzing the application of information and communication technologies in the function of Carpooling. In previous studies (Grgurevic et al., 2014) the analysis was made on the application of information and communication technologies in the function of carpooling. The aim of research (COMPOSE, 2013) was to collect useful knowledge about the current and future exploitation possibilities and solutions in the area of IoT.

In order to determine the possibility of the application of the IoT concept in the function of carpooling, i.e. its carsharing option, a survey has been made among the target group of users of modern technologies who are familiar with the issues of carpooling (the survey area is the City of Zagreb, Republic of Croatia). The survey was carried out in April and May 2015 in three different ways: by electronic mail, by web survey (link: http://www.fpz.unizg.hr/autozasve) and by interview. The surveyed group comprised respondents in the age between 18 and 65, and it covered the employed citizens and full-time students. These two groups of respondents represent the active population, considered to be commuting every day in the Zagreb transport network.

The method of collecting data for the need of research is shown in Table 2. In order to avoid, i.e. eliminate epistemological difficulties, the survey was applied on the sample of respondents that have almost equal level of education. Thus, every respondent's answer has the same value and equally forms the statistical mass. The survey encompassed a total of 429 respondents. The biggest number of respondents was collected via web survey, and it amounts to $89.044 \%$.

\begin{tabular}{|l|c|c|}
\hline $\begin{array}{l}\text { Method of collecting } \\
\text { data }\end{array}$ & Number of respondents & $\begin{array}{c}\text { Percentage of respondents } \\
\text { (\%) }\end{array}$ \\
\hline e-mail & 32 & 7.459 \\
\hline web surveys & 382 & 89.044 \\
\hline interview & 15 & 3.497 \\
\hline Total & 429 & 100 \\
\hline
\end{tabular}

Tab. 2. Method of collecting data for research purposes (2015)

The number of the surveyed employees in 2015 was 223 (51.981\%), and of fulltime students 206 (48.019\%). The target group and number of respondents is shown in Table 3. Statistical error for 223 employees was $E=5.51 \%$ and for 206 full-time students it was $\mathrm{E}=5.72 \%$. The target group and the number of respondents represent a representative sample for research. Table 3 shows the number of respondents $(n)$ according to the groups, percentage of respondents (in \%), confidence level $(c)$, share of answers $(r)$, total quantity of target population $(N)$ and margin of error $(E)$. A 
Grgurevic, I.; Perakovic, D.; Forenbacher, I. \& Milinovic, T.: Application of the Int... potential limitation is the sample size. Further data should be collected in order to generalize results to a larger population.

\begin{tabular}{|l|c|c|}
\hline Target group of respondents & Employees & Full-time students \\
\hline Number of respondents $n$ & 223 & 206 \\
\hline $\begin{array}{l}\text { Percentage of respondents (in } \\
\%)\end{array}$ & 51.981 & 48.019 \\
\hline Confidence level $c$ (in \%) & 90 & 90 \\
\hline Share of answers $r$ & $50 \%$ & $50 \%$ \\
\hline Total size of population $N$ & 397,365 & 64,695 \\
\hline Margin of error $E(\%)$ & 5.51 & 5.72 \\
\hline
\end{tabular}

Tab. 3. Target group and number of respondents (2015)

From 223 surveyed employees there were 118 male respondents (in percentage $52.914 \%)$ and 105 female respondents (47.085\%). From 206 surveyed full-time students there were 98 male respondents (in percentages 47.572\%) and 108 female respondents $(52.427 \%)$.

For defining of the representative sample it was necessary to determine the frequency of using carpooling (the carsharing model does not yet exist in the city of Zagreb) by passenger cars, and the frequency was classified according to the period of usage (never, sometimes, once a week, 2-3 days a week, and 4-5 days a week). The option "sometimes", when it comes to the frequency of usage, means monthly usage of carpooling 3-4 times a week. Frequency of carpooling is shown in Table 4.

\begin{tabular}{|c|l|c|c|}
\hline Ord. No. & $\begin{array}{l}\text { Frequency of using } \\
\text { carpooling }\end{array}$ & Frequency & Percentage (\%) \\
\hline A1 & never & 61 & 14.286 \\
\hline A2 & $\begin{array}{l}\text { sometimes } \\
\text { (monthly 3-4 days) }\end{array}$ & 83 & 19.438 \\
\hline A3 & once a week & 75 & 17.564 \\
\hline A4 & 2-3 days a week & 112 & 26.230 \\
\hline A5 & 4-5 days a week & 96 & 22.482 \\
\hline & Total & 427 & 100 \\
\hline A6 & $\begin{array}{l}\text { did not respond to the survey } \\
\text { in full }\end{array}$ & 2 & 0.466 \\
\hline & Total & 429 & - \\
\hline
\end{tabular}

Tab. 4. Frequency of using carpooling 
When it comes to the mode of using passenger cars and according to the data there were $37.978 \%$ of persons who were usually acting as drivers. The majority of persons are usually passengers, and in the research they accounted for $50.547 \%$ (Table 5).

The respondents who never use the carpooling option (A1) and the respondents who did not respond to the survey in full (A6) were eliminated from further analysis. Thus, the analysis takes into account the respondents who are designated as A2, A3, A4 and A5 shown in Table 4. Therefore, the number of the respondents taken into account was 366. From 366 respondents, there were 191 employees with residence in the City of Zagreb (52.186\%) and 175 full-time students studying in the City of Zagreb (47.814\%) and who prevailingly use the carpooling services. The characteristics of the persons using carpooling/ridesharing is shown in Table 5.

\begin{tabular}{|l|c|c|}
\hline $\begin{array}{l}\text { Characteristics of persons using } \\
\text { carpooling }\end{array}$ & Frequency & Percentage (\%) \\
\hline I usually drive & 139 & 37.978 \\
\hline I am usually a passenger & 185 & 50.547 \\
\hline $\begin{array}{l}\text { Both (sometimes I am a driver and } \\
\text { sometimes a passenger) }\end{array}$ & 42 & 11.475 \\
\hline Considered respondents & 366 & 100 \\
\hline
\end{tabular}

Tab. 5. Characteristic of persons using carpooling/ridesharing

When it comes to the driving license (B category) there was no significant difference between the two observed groups of users (employees and full-time students). Out of 191 employees, 170 respondents had a driving license, whereas 21 respondents did not. In percentages, $89.005 \%$ of surveyed employees owned a driving license and $10.995 \%$ of respondents did not have a driving license. In the observed student population, there were 144 respondents with a driving license (82.286\%), and 31 did not have a driving license (17.714\%). These data show minor variations between the two observed groups.

The respondents were asked in the survey about the place of residence and they could choose among the following options: urban, suburban and rural areas. There were $71.858 \%$ of respondents (263) living in the urban area, $18.852 \%$ (69) in suburban and $9.290 \%$ (34) in the rural area.

The data shown in the paper present only a small amount of conducted research and they were disseminated in order to determine the representativeness of the sample in the function of analysis and development of the application of the IoT concept for the purpose of carsharing system. Further in the text the usage of information and communication technologies and services (ICTS) from the user's point of view in the function of carsharing has been analyzed.

\section{Survey results}

Information and communication technologies are a major driving force and integrator of the carsharing users who represent a special segment and the subject of 
Grgurevic, I.; Perakovic, D.; Forenbacher, I. \& Milinovic, T.: Application of the Int...

the conducted analysis. The analyzed results from the survey include also data analysis on the subject of using information and communication technology in connecting with other users. During the survey the opinions and attitudes of the users of modern technologies and carsharing have been established on the matters of:

- Significance of ICTS in promoting carsharing system,

- Functionality of IoT that are vital for the improvement of the carsharing system,

- Most important factors associated with the application of the IoT concept, and

- Applicability of IoT in the carsharing system.

The significance of ICTS in connecting carpooling users and elements of carsharing systems is shown in Figure 1. It is visible how vital that impact is on the future development of the carsharing model.

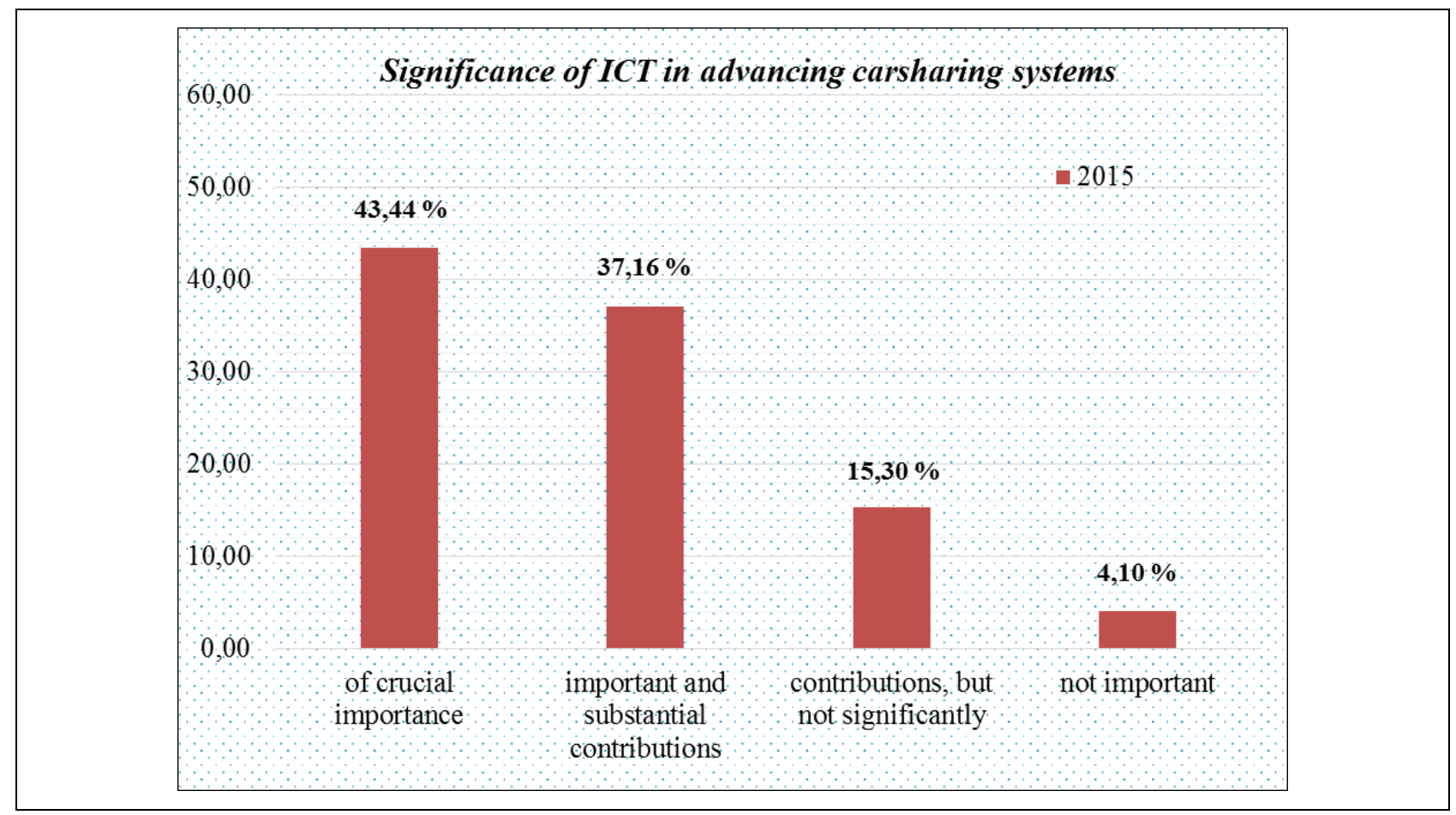

Fig. 1. Survey results: Significance of ICT in advancing carsharing systems

Almost half of the respondents (159-43.44\%) have chosen significance of ICTS as of crucial importance. More than one third of respondents $(136-37.16 \%)$ have chosen significance of ICTS as important and substantial contribution, 56 respondents (15.30\%) have chosen contributions, but not significantly, and only 15 respondents $(4.10 \%)$ have chosen not important. Such results can be interpreted as the expected ones regarding the development of ICTS and its possibilities of implementation in the traffic environment.

According to available sources many functionalities of IoT can be recognized (McEwen \& Cassimally, 2013; Yu \& Bai, 2012; COMPOSE, 2013). However, IoT functionalities that have been recognized as significant for the carsharing system are: fast development of new applications, fast and easy use of new data sources or objects with performance of the platform (scalability, reliability, etc.) and interoperability among heterogonous objects. These functionalities represent an upgrade and integration of the current functions within the carsharing system. 
Based on the recognized functionalities, the survey included questions in order to obtain opinions and attitudes from the target group of respondents (explained in Section 2).

The most important factors associated with using IoT are shown in Figure 2. Factors that have been identified are flexibility and easy application (extensibility), openness of solutions (adapting programs with open code or open application-program interfaces), scalability, IoT security (privacy and trust), availability of IoT solutions and increased level of security (fewer traffic accidents and lesser consequences). These factors represent the basic functionalities for the carsharing system user, thus realizing, apart from openness and availability of IoT solutions, also faster, safer, more scalable and more flexible level of service. In this context the scalability represents a property of IoT that can be adapted to load increase and decrease, thus being of special importance for the operators and experts in defining the solutions in the field of IoT.

The respondents graded the factors from 1 to 5, one (1) being the worst and five (5) the best grade. Each factor had to be graded separately. The best graded factors were availability of IoT solutions (266 respondents have graded this application with 5), IoT security, privacy and trust (258 respondents - grade 5), flexibility and easy application (234 respondents - grade 5), and the worst graded factor was scalability (96 respondents - grade 5). IoT security is the area of endeavor concerned with safeguarding connected devices and networks in the IoT. From the survey, scalability and openness of the solutions seem to be less important from the respondents' perspective. However, particularly concerning openness, a more detailed investigation should be performed.

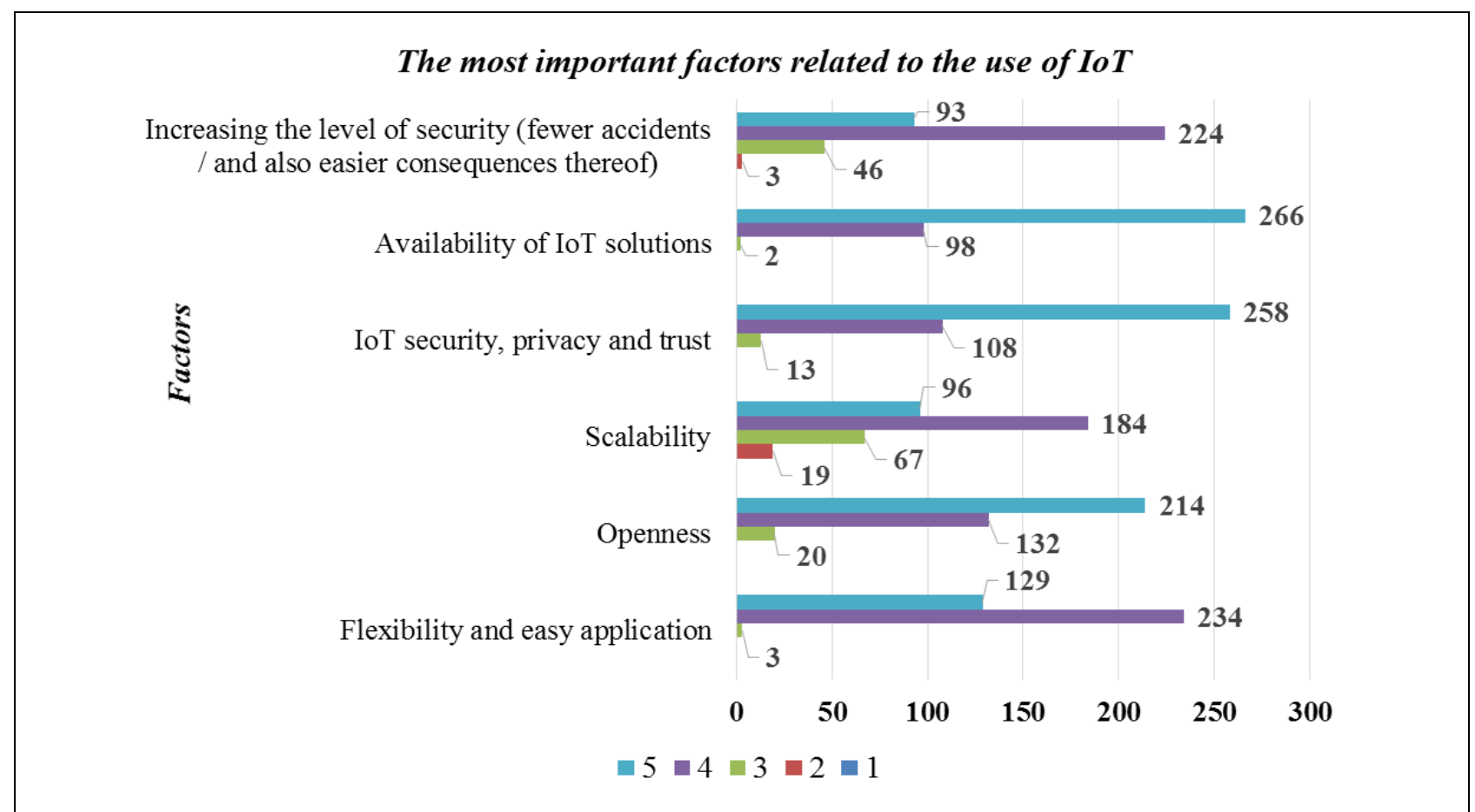

Fig. 2. Survey results: The most important factors related to the use of IoT

In the following part of this paper we have explored the application of the IoT solutions for the purposes of carsharing system. The respondents graded the 
applications of the IoT solutions, one (1) being the worst and five (5) the best grade. Each IoT solution had to be graded separetely. Figure 3 shows the applications of the IoT solutions in the carsharing system.

It should be emphasized that each of the recognized IoT applications can solve one of the practical problems of the carsharing system. The respondents have answered this question as the users of carpooling services, so that the given answers had been expected accordingly. The respondents have graded the following as the best applications of IoT solutions on carsharing: vehicle availability tracking in real-time (235 respondents have graded this application with 5), data transfer from car for the purposes of monitoring vehicle state (206 respondents - grade 5) and easier real-time journey planning and avoiding congestions (204 respondents - grade 5). The worst graded were: parking places availability check ( 72 respondents - grade 5), location and navigational data on vehicle (78 respondents - grade 5) and enhanced fleet management (96 respondents - grade 5).

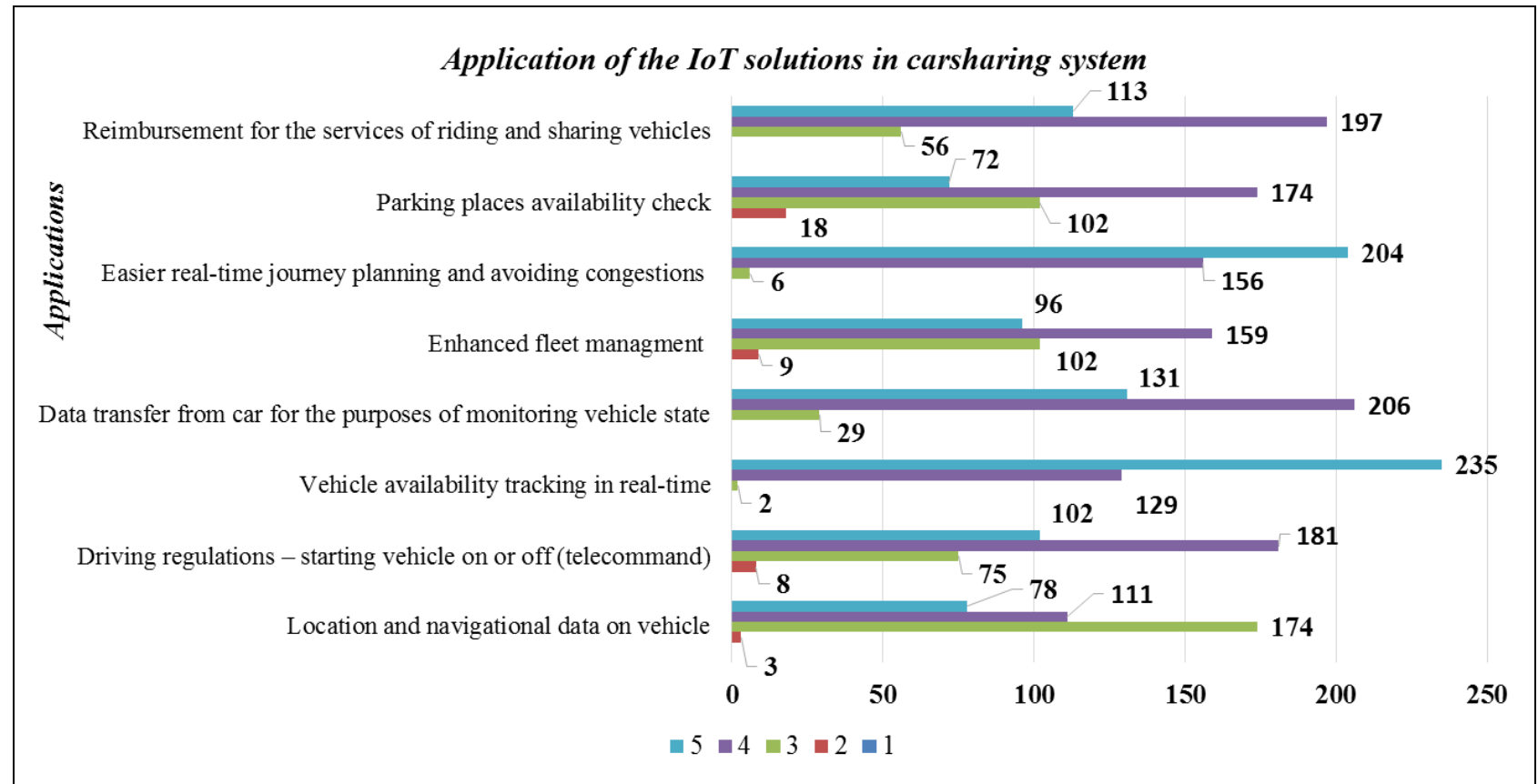

Fig. 3. Survey results: Application of the IoT solutions in carsharing system

The worst graded applications of IoT solutions can be explained by the fact that there exist already a number of standard services and applications that efficiently solve the mentioned issues and have not been recognized as yet as significant within the development possibilities of the IoT concept. For instance, checking of parking space availability is solved by the System of informing and guiding to free parking spaces and several adapted smartphone applications. The location and navigation segment has been covered well by the Location Based Services (LBS) which, using the mobile telecommunication infrastructure, provide the carsharing system users with relevant information depending on their current location of the carsharing users, thus providing Value Added Service (VAS). As part of the future IoT concept, fleet management is of 
more importance for the business users, so that the target group of private users did not indicate it as significant.

It is important to observe the development of carsharing system as one more possibility of transport in the cities and it is important to plan accordingly the common platforms (together with other public transportation modes) based on information and communication technologies and application of IoT.

\section{Conclusion}

Sudden development of the IoT concept is expected to bring various possibilities of its application in different transport services. Carpooling and carsharing are among the new growing transport services in the developed cities. Carsharing development will depend on the future evolution of information and communication technologies and application of IoT. Four IoT functionalities are especially important for the carsharing system: fast development of new application, interoperability among heterogonous objects, fast and easy use of new data sources or objects with performance of the platform (scalability, reliability, etc.). The speed and the ease of use are the main requirements for the upgrade of carsharing by using the IoT concept. Frequent use will make these solutions popular and it will be easier to transfer them to general public. Fast application development gives greater opportunities to every smartphone owner. With fast development they will be able to utilize many IoT advantages through various new smartphone applications.

According to the carried out research the most important factors associated with using IoT are availability of IoT solutions (266 respondents - grade 5), IoT security, privacy and trust (258 respondents - grade 5), and flexibility and easy application (234 respondents - grade 5).

Analyzing the available relevant studies it was determined that until now this segment and problem of research (application of the IoT in carsharing system) has not been studied, either from the position of the users, nor from the position of experts. This paper has determined the opinions and attitudes of modern technology and carsharing users on the matter of significance of ICTS in developing carsharing systems. It is also important to recognize the most valuable factors associated with the IoT concept and also functionalities and applications of IoT for the purposes of carsharing system development.

The results of the research analysis were used to identify the potential application of IoT solutions in the development of the carsharing model. The respondents have graded as the best applications of IoT solutions on carsharing: vehicle availability tracking in real-time (235 respondents - grade 5), data transfer from car for the purposes of monitoring vehicle state (206 respondents - grade 5) and easier real-time journey planning and avoiding congestions (204 respondents - grade 5). Carsharing system in combination with the IoT concept represents a good possibility for solving the major traffic and transport problems in the cities (traffic congestion, low vehicle occupancy, pollution of the environment, etc.). It is important to find first the best and 
Grgurevic, I.; Perakovic, D.; Forenbacher, I. \& Milinovic, T.: Application of the Int...

the most useful field of work for its application in order to create synergy between the IoT concept and the carsharing system.

The suggestion for future studies (future plans) is to conduct detailed analysis of all carsharing system shareholders (for example: traffic experts, carsharing operators, and topical associations/NGOs). The results from the conducted research can be applied in the process of planning the development of new services and segments of the carsharing system by applying the information and communication technologies and the IoT concept.

\section{Acknowledgements}

This research has been carried out as part of the project "Possibilities of Applying Information and Communication Technologies and Services in the function of Carpooling Systems" (No. 251-76-01-15-13) supported by the Faculty of Transport and Traffic Sciences, University of Zagreb, Programme for Research, 2015.

\section{References}

Atzoria, L.; Ierab, A. \& Morabito, G. (2010). The Internet of Things: A survey, Computer Networks, The International Journal of Computer and Telecommunications Networking, ISSN: 1389-1286, Vol. 54, No. 15, pp. 2787-2805

Chen, T.Y.; Wei, H.W.; Hsu, N-I \& Shih, W.K. (2013). A IoT Application of Safe Building in IPv6 Network Environment, The 37th Annual International Computer Software \& Applications Conference (COMPSAC 2013), Conference proceedings of the COMPSAC 2013, IEEE, pp. 748-753, ISBN: 978-0-7695-4986-6, Kyoto, Japan Cisco (Internet Business Solutions Group), (2011). The Internet of Things, How the Next Evolution of the Internet is Changing Everything, White Paper, April 2011

COMPOSE (2013). IoT Survey Outcomes, COMPOSE Collaborative Project, Collaborative Open Market to Place Objects at your Service, pp. 1-17., http://www.compose-

project.eu/sites/default/files/news/COMPOSE\%20IoT\%20Survey\%20Outcomes\%20 v1\%200.doc., Accesed on:2015-03-15

Gao, D.Q.; Zhang, Y.Y. \& Li, X.Z. (2012). The Internet of Things for Electric Vehicles: Wide Area Charging-Swap Information Perception, Transmission and Application, Advanced Materials Research, Vols. 608-609, Dec. 2012, pp. 1560-1565

Geng-yong, C. \& Yu-ma, T. (2013). Safety Emergency Management System Design of Road Dangerous Goods Transport Based on IoT, Logistics Sci-Tech Journal, ISSN: 1002-3100, Vol. 1

Grgurevic, I. (2013). Determining carpooling trip origin locations in urban areas, Ph.D. thesis, University of Zagreb, Faculty of Transport and Traffic Sciences, Zagreb

Grgurevic, I.; Stancic, A.; Milinovic, T. \& Huncek, M. (2014). Application of Information and Communication Technologies and Services in Carpooling Systems, RCITD 2014, Proceedings of Research Conference In Technical Disciplines, Zilina, 
EDIS - Publishing Institution of the University of Zilina, pp. 98-103, ISBN: 978-80554-0948-1, Zilina, Slovakia

Huang, J.M. (2013). Research on Internet of Vehicles and its Application in Intelligent Transportation, Applied Mechanics and Materials, Vols. 321-324, Chapter 21: Computer Networks and Communication, Edited by P. Yarlagadda and Y-H. Kim, pp. 2818-2821, ISBN 978303785694 9, Guangzhou, China

Kim J. \& Lee, J. (2012). Cluster-Based Mobility Supporting WMN for IoT Networks, Proceedings of the IEEE International Conference on Green Computing and Communications (GreenCom '12), IEEE, pp. 700-703, ISBN: 978-1-4673-5146-1, Besançon, France

Kos, A.; Sedlar, U.; Sterle, J.; Volk, M.; Bester, J. \& Bajec, M. (2013). Network monitoring applications based on IoT system, 18th European Conference on Network and Optical Communications \& 8th Conference on Optical Cabling and Infrastructure (NOC-OC\&I 2013), Conference proceedings, IEEE, 2013, pp. 69-74, ISBN: 978-14673-5821-7, Graz, Austria

KuBo (2014). The Research of IoT Based on RFID Technology, 7th International Conference on Intelligent Computation Technology and Automation (ICICTA), Conference proceedings of the ICICTA, IEEE, pp. 832-835, ISBN: 978-1-4799-66356, Changsha, China

Li, Y.; Sun, G.; Li, X. \& Mu, W. (2010). Research for Advanced Public Transport Solutions Based on the IoT, ICLEM 2010, Conference proceedings of ICLEM, pp. 520-525, ISBN: 978-0-7844-1139-1

Lian-Zhou, G. (2013). Study on Intelligent Monitoring System of Road Transport of Dangerous Goods Based on Internet of Things Technology, Journal of Logistics Engineering and Management, Vol 3

McEwen, A. \& Cassimally, H. (2013). Designing the Internet of Things, 1st Edition, John Wiley \& Sons, p. 336, ISBN: 978-1118430620

Ming, D.; \& Xu, L. (2012). Strategy of Applying Internet of Things Technology in Transportation Industry, Journal of Computer and Communications, Issue 4, pp. 142 144.

Nam, J.; Park, J.H. \& Chung, J.M. (2014). Performance analysis of cooperative content delivery in wireless IoT networks, 18th International Symposium on Consumer Electronics (ISCE 2014), Conference proceedings of the ISCE 2014, IEEE, Jeju, Korea, pp. 1-2.

Ping, L. \& Xiao-dong, L. (2012). Study on IoT Security, Information Security and Communications Privacy Journal, ISSN: 1930-1650, Vol. 2

Selvapriya, P.R. \& Mundada, M.R. (2015). IoT based Bus Transport System in Bangalore, International Journal of Engineering and Technical Research (IJETR), ISSN: 2321-0869, Vol. 3, Issue 2, pp. 276-286

Shi-ling, M. (2012). Application of IoT in Construction of Smart City, Internet of Things Technologies (IOTT) Journal, Vol. 2

Slavulj, M.; Grgurevic, I. \& Golubic, J. (2014). Analysis of possible risks in introducing congestion charging and carpooling measures in Zagreb, Public Mobility Systems, 
Grgurevic, I.; Perakovic, D.; Forenbacher, I. \& Milinovic, T.: Application of the Int...

University of Pisa, Italy, Southampton, Wessex Institute of Technology: WIT Press, ISBN: 978-1-84564-908-1, pp. 51-62, Southampton, UK

Sukode, S. \& Gite, S. (2015). Vehicle Traffic Congestion Control \& Monitoring System in IoT, International Journal of Applied Engineering Research, ISSN 0973-4562, Vol. 10, No. 8, pp. 19513-19523

Sun, R.C.; Piao, Y.; Wang, Y. \& Wang, H. (2012). Parking Guidance Control System Based on Internet of Things, Applied Mechanics and Materials, Vol. 273, Chapter 8: Control and Information Engineering, Edited by S. Zhong and Y. Zhang, pp. 641-645 Tan, J. \& Koo, S.G.M. (2014). A Survey of Technologies in Internet of Things, International Conference on Distributed Computing in Sensor Systems (DCOSS), Conference proceedings of DCOSS, IEEE, Marina Del Rey, CA, USA, pp. 269-274. Wang, D.P. \& Hu, K.Y. (2014). Research on Path Optimization of Urban Traffic Guidance System, Applied Mechanics and Materials, Chapter 6: Communication, Processing of Signal and Data, Information Technologies, Edited by L. Qiang, Vol. 624, pp. 520-523

Xie M. (2011). The Application on the Internet of Things on Transport Logistics, Journal of Logistics Engineering and Management, Vol. 33(5), pp. 10-11

Xua, R.; Shuang-Hua, Y.; Li, P. \& Cao, J. (2014). IoT architecture design for 6LoWPAN enabled Federated Sensor Network, 11th World Congress on Intelligent Control and Automation (WCICA 2014), Conference proceedings of the WCICA 2014, IEEE, Shenyang, China, pp. 2997-3002

Yang Z.; Peng, Y.; Yue, Y.; Wang, X.; Yang, Y. \& Liu, W. (2011). Study and application on the architecture and key technologies for IoT, International Conference on Multimedia Technology (ICMT), Conference proceedings of ICMT, IEEE, pp. 747751, ISBN: 978-1-61284-771-9, Hangzhou, China

Yu, C. (2011). Research and Design of Logistics Management System based on Internet of Things, 2nd International Conference on Artificial Intelligence, Management Science and Electronic Commerce (AIMSEC), Conference proceedings of AIMSEC 2011, IEEE, pp. 6314-6317, ISBN: 978-1-4577-0535-9, Deng Feng, China

Yu, X. \& Bai, Y. (2012). Internet of Things and its Application in Intelligent Logistics, Applied Mechanics and Materials, Chapter 21: The Internet of Things, Edited by P. Yarlagadda and Y-H. Kim, Vols. 241-244, pp. 3201-3204

Zhang, M.; Yu, T. \& Zhai, G.F. (2011). Smart Transport System Based on The Internet of Things, Applied Mechanics and Materials, Vols. 48-49, Edited by Z. Hou, pp. 10731076

Zhang, S.J. \& Chen, S.Y. (2014). Design \& Implementation of Real-Time Broadcast System of Urban Public Transport Crowding Index Based on the Internet of Things, Advanced Materials Research, Chapter 8: Theory and Practice of Information Technologies and Communications, Edited by X.Y. Huang, X.B. Zhu, K.L. Xu and J.H. Wu, Vols. 1049-1050, pp. 1753-1758 